\title{
Mixed Stream Test Rig (MISTER) Startup Report
}

February 2011

The INL is a

U.S. Department of Energy

National Laboratory

operated by

Battelle Energy Alliance

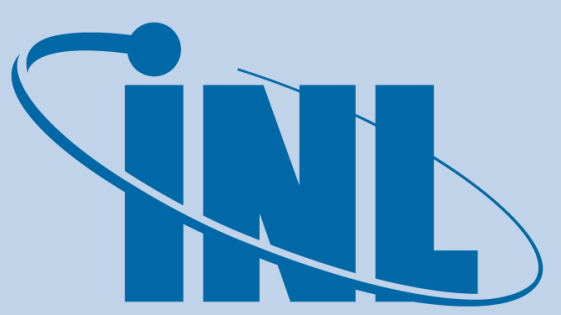

Idaho National Laboratory

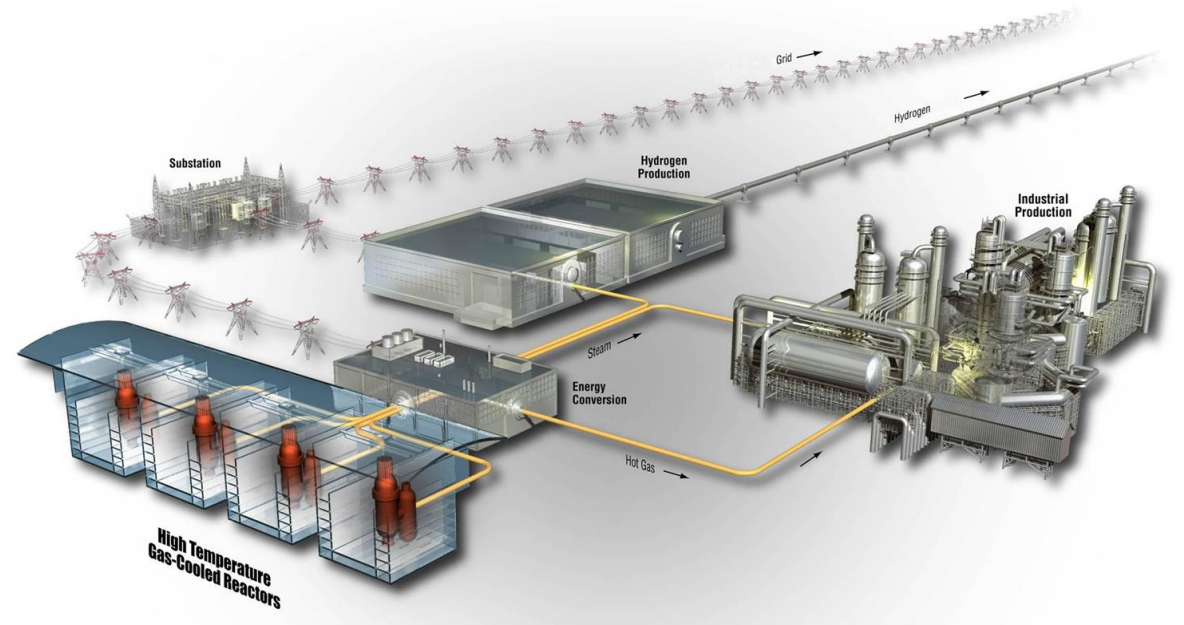




\section{DISCLAIMER}

This information was prepared as an account of work sponsored by an agency of the U.S. Government. Neither the U.S. Government nor any agency thereof, nor any of their employees, makes any warranty, expressed or implied, or assumes any legal liability or responsibility for the accuracy, completeness, or usefulness, of any information, apparatus, product, or process disclosed, or represents that its use would not infringe privately owned rights. References herein to any specific commercial product, process, or service by trade name, trade mark, manufacturer, or otherwise, does not necessarily constitute or imply its endorsement, recommendation, or favoring by the U.S. Government or any agency thereof. The views and opinions of authors expressed herein do not necessarily state or reflect those of the U.S. Government or any agency thereof. 


\section{Mixed Stream Test Rig (MISTER) Startup Report}

February 2011

Idaho National Laboratory

Next Generation Nuclear Plant Project

Idaho Falls, Idaho 83415

Prepared for the

U.S. Department of Energy

Office of Nuclear Energy

Under DOE Idaho Operations Office

Contract DE-AC07-05ID14517 



\title{
Next Generation Nuclear Plant Project
}

\section{Mixed Stream Test Rig (MISTER) Startup Report}

\author{
INL/EXT-11-20961
}

February 2011

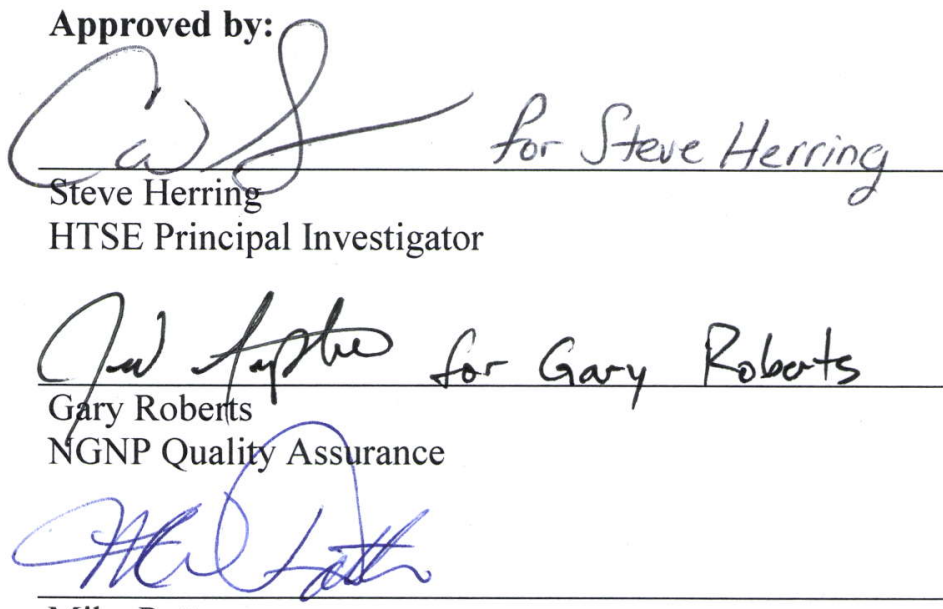

Mike Patterson

NGNP Process Heat Applications Manager

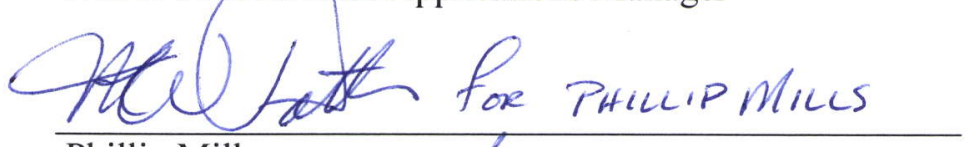

Phillip Mills

NGNP Engineering Diregtor (acting)

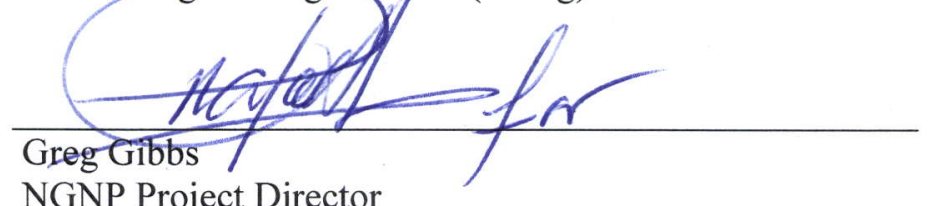

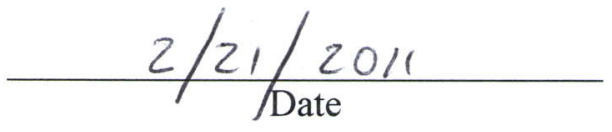
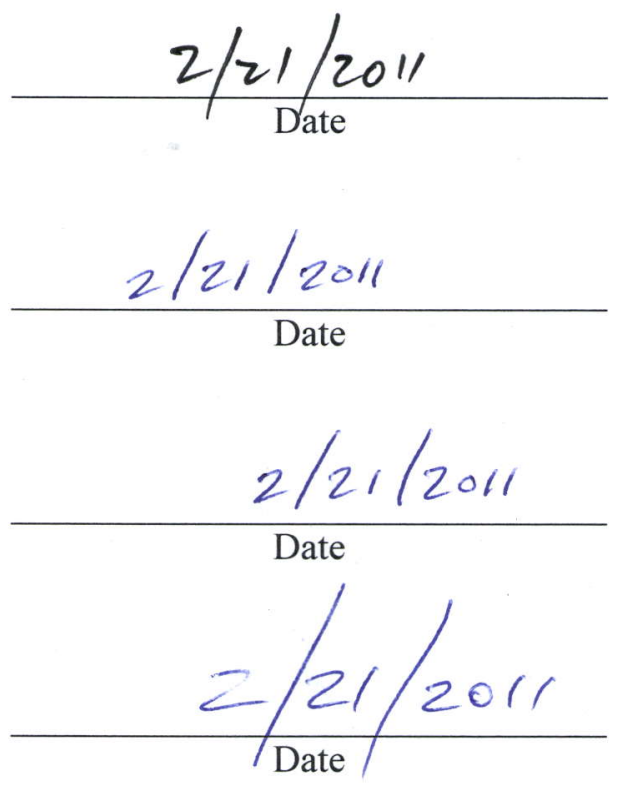



\section{SUMMARY}

This report describes the work accomplished to design, assemble, start up and initiate testing in the Mixed Stream Test Rig (MISTER) at Idaho National Laboratory (INL). It describes the reasons for establishing this capability, physical configuration of the test equipment, operations methodology, initial success, and plans for completing the initial 1,000-hour test of high temperature specimens.

MISTER was assembled in FY 2010 to test high temperature materials within environments of gas compositions that are expected in the high temperature steam electrolysis (HTSE) hydrogen production process. The test system is designed to provide realistic environments for studying the effects of high-temperature gas mixtures upon material samples. It does this with two separate gas streams of variable composition within a single furnace, exposing material samples to the gases at temperatures up to $1100^{\circ} \mathrm{C}$. Understanding the resulting material corrosion rates will help inform materials selection and qualification to ensure successful future performance. The initial test focuses on potential alloys for use in the oxygen and hydrogen streams from the HTSE process, although MISTER is also capable of controlling mixtures of $\mathrm{CO}, \mathrm{CO}_{2}$, $\mathrm{N}_{2}$, and other gases.

Table S-1 provides a list of commercial alloys selected for the first MISTER test, which was initiated at $800^{\circ} \mathrm{C}$ to reflect the gas temperatures at the HTSE anode and cathode. The hydrogen stream contains $33 \%$ moisture and the oxygen stream contains 50\% nitrogen, which reflects expected HTSE gas conditions. The three Haynes alloys in Table S-1 were selected because of superior performance in previous INL HTSE testing. The final alloy was chosen because it has been selected for use in several NGNP heat transport system components. Alloy $800 \mathrm{H}$ is already listed in the ASME nuclear section (ASME Code Section III Division 1), although the maximum use temperature and time need to be increased to support use at the conditions expected for nuclear-integrated operations (including hydrogen production).

Table S-1. Alloys selected for MISTER testing.

\begin{tabular}{|lll|}
\hline \multicolumn{1}{|c}{ Alloy } & Oxide & Expected Performance \\
\hline Haynes 214 & alumina & Excellent \\
Haynes 230 & chromia & Excellent \\
Haynes HR-120 & chromia & Good \\
Incoloy $800 \mathrm{H}$ & chromia & Good* \\
& & \\
$* \quad$ ASME codified for nuclear applications at lower temperatures. & \\
\hline
\end{tabular}

Each material type is being tested in both the hydrogen and oxygen streams and each will have a sample removed after approximately 2 days, 1 week, 3 weeks, and 6 weeks, for a total of 32 specimens.

Specimens were inserted into the MISTER Furnace on January 10, 2011, and furnace heat-up was initiated. When the furnace reached operating temperature the morning of January 11, 2011, the specified gas streams were introduced. The gas streams were isolated on the afternoon of January 12 and the furnace turned 
off so it could cool to approximately ambient temperature, to allow the first set of specimens to be removed the morning of January 13. Furnace heat up and cool down requires from 6 to 8 hours.

The current MISTER configuration represents an enhanced INL capability for testing materials in representative gas conditions, which is crucial for applied research with balance of plant systems in support of solid-oxide electrolysis cell development. Many process applications considered for the NGNP will require corrosion testing in high temperature gas mixtures, which MISTER is capable of supplying. In addition to the high temperatures, high pressures exist in many of these process applications. MISTER was thus designed and built so it could, with minor modifications, also provide high pressure testing up to 1,000 psi. With further modification, it could test materials subjected to mechanical loading or pressure cycling at these high temperatures and pressures within a variety of gas compositions. Testing in these conditions will significantly advance the understanding of materials performance in representative environments for future heat exchangers, steam generators, circulators, seals, and instrument and control components. Other programs that could potentially benefit from testing in MISTER include life extension programs, hybrid energy systems and advanced reactor concepts. 


\section{CONTENTS}

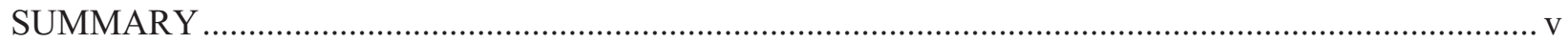

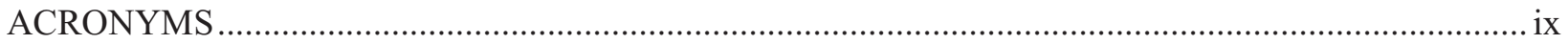

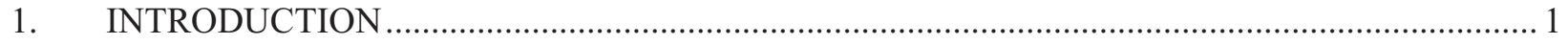

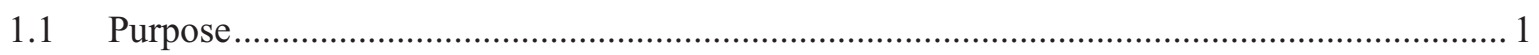

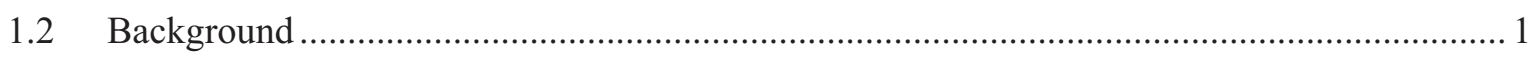

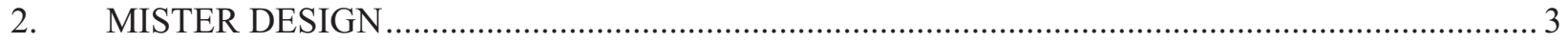

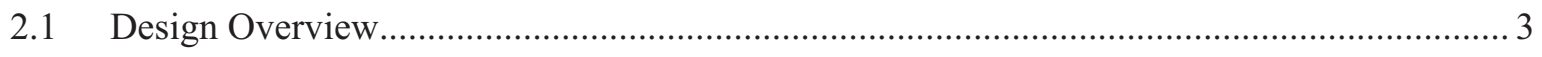

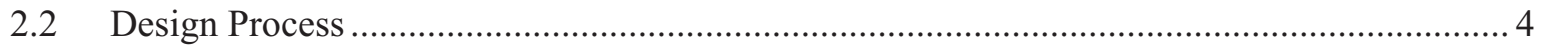

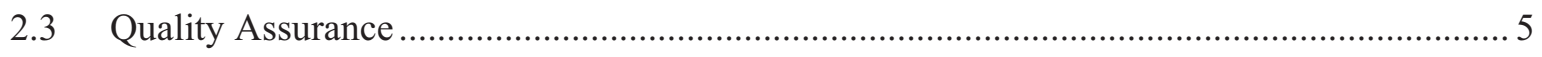

2.4 Safety Authorization and Hazard Mitigations................................................................. 5

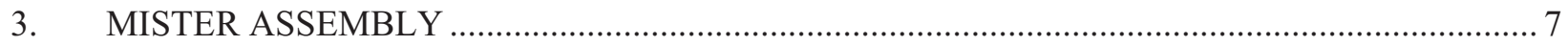

3.1 Legacy Equipment_High Temperature Corrosion Experiment............................................ 7

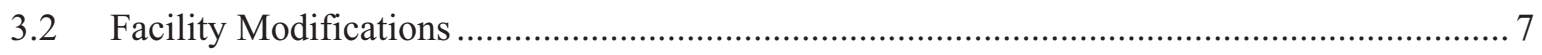

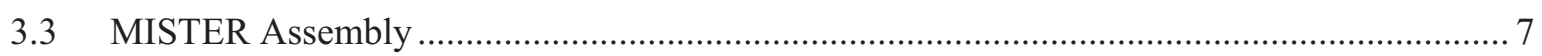

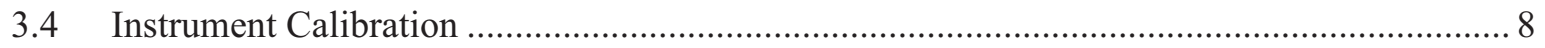

3.5 Physical Description of MISTER Subsystems............................................................... 8

3.5.1 Gas Supply and Automatic Shutoff/Purge Manifold ......................................... 8

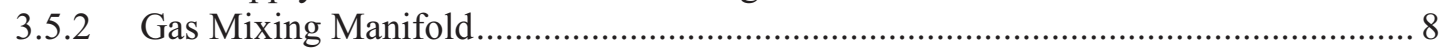

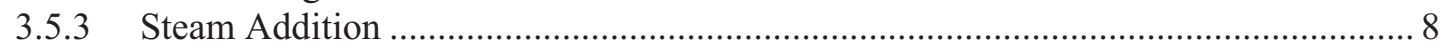

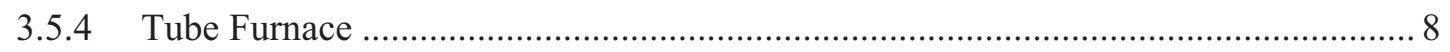

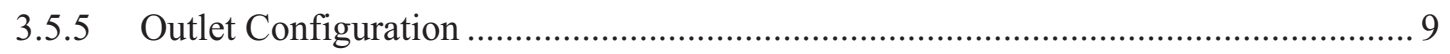

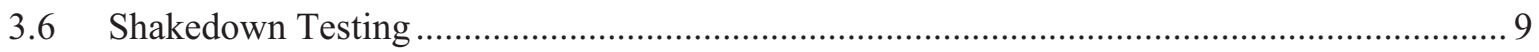

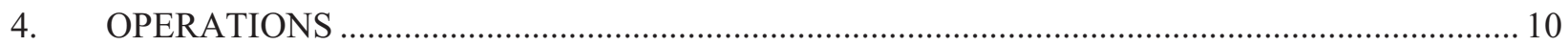

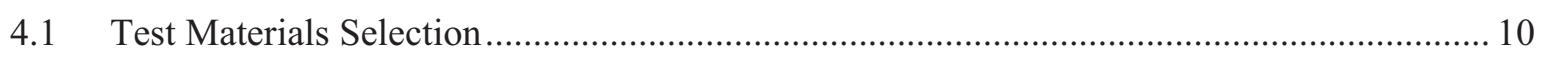

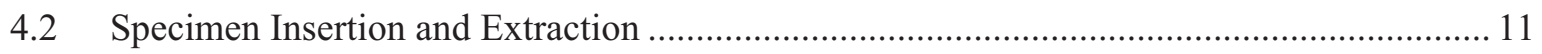

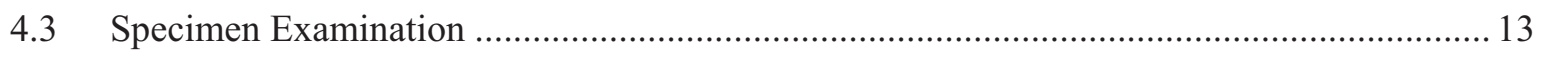

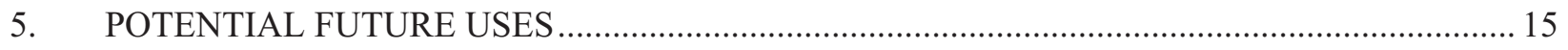

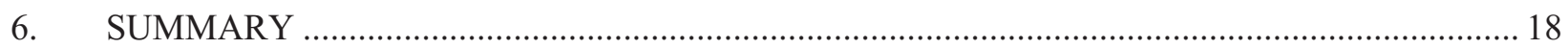

\section{FIGURES}

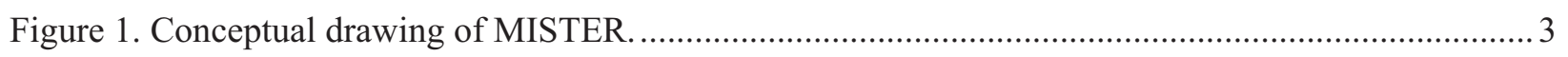

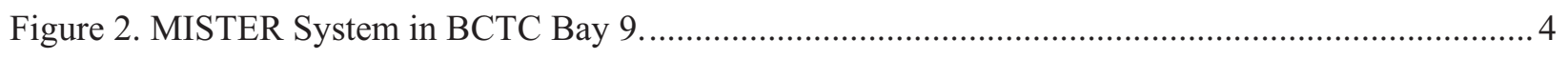

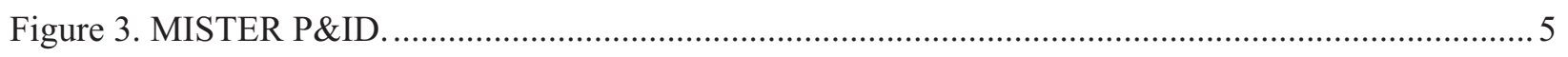

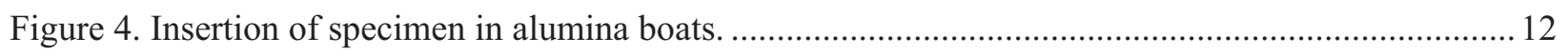

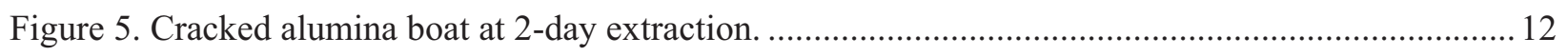


Figure 6. Loading specimen into MISTER using quartz boats.

Figure 7. Color photograph of $1 \mathrm{~cm}^{2}$ specimens exposed to hydrogen/steam gas stream. Top row was exposed for 25 hours and bottom row for 125 hours.

Figure 8. Color photograph of $1 \mathrm{~cm}^{2}$ specimens exposed to oxygen/nitrogen gas stream. Top row was exposed for 25 hours and bottom row for 125 hours.

Figure 9. MISTER is part of a suite of complementary testing capabilities.

\section{TABLES}

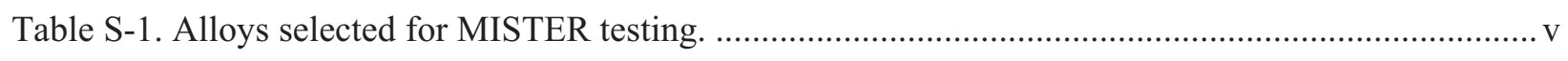

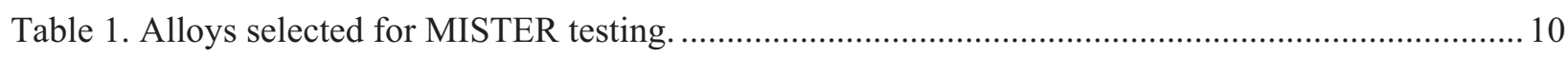

Table 2. Test matrix for testing HTSE cathode gas environment. .......................................................... 11

Table 3. Test matrix for testing HTSE anode gas environment. ........................................................ 11 


\section{ACRONYMS}

$\begin{array}{ll}\text { ASME } & \text { American Society of Mechanical Engineers } \\ \text { BCTC } & \text { Bonneville County Technology Center } \\ \text { BOP } & \text { Balance of Plant } \\ \text { DOE } & \text { Department of Energy } \\ \text { HTSE } & \text { high temperature steam electrolysis } \\ \text { INL } & \text { Idaho National Laboratory } \\ \text { LFL } & \text { lower flammability level } \\ \text { LI } & \text { Laboratory Instruction } \\ \text { MISTER } & \text { Mixed Stream Test Rig } \\ \text { NGNP } & \text { Next Generation Nuclear Plant } \\ \text { OSU } & \text { Ohio State University } \\ \text { QLD } & \text { Quality Level Determination } \\ \text { R\&D } & \text { research and development } \\ \text { SEM } & \text { scanning electron microscopy } \\ \text { SOEC } & \text { solid-oxide electrolysis cell } \\ \text { SPECTR } & \text { Small Pressure Cycling Test Rig } \\ \text { TLV } & \text { Threshold Limit Value }\end{array}$




\section{Mixed Stream Test Rig (MISTER) Startup Report}

\section{INTRODUCTION}

\subsection{Purpose}

This report describes the work accomplished to assemble, start-up, and initiate testing in the Mixed Stream Test Rig (MISTER) at Idaho National Laboratory (INL). It describes the reasons for establishing this capability, physical configuration of the test equipment, operations methodology, initial operations, and plans to continue and complete the initial 1,000-hour test of high temperature specimens.

MISTER was assembled in FY 2010 to test high temperature materials within environments of gas compositions that are expected in the high temperature steam electrolysis (HTSE) hydrogen production process. The test system is designed to provide realistic environments for studying the effects of high-temperature gas mixtures upon material samples. It does this with two separate streams within a single furnace of hydrogen and oxygen mixtures that can be exposed to temperatures up to $1100^{\circ} \mathrm{C}$. Understanding the resulting material corrosion rates will help inform materials selection and qualification to ensure successful future performance.

The current MISTER configuration represents an enhanced capability for INL. MISTER was also designed and built so that, with minor modifications, it can provide high pressure testing at up to $7 \mathrm{MPa}$ $(1,000 \mathrm{psi})$. With further modification, it could test materials subjected to load or cycling at these high temperatures and pressures within a variety of gas compositions. This testing will significantly advance the understanding of materials performance in the HTSE process and provide the capability for testing materials in other high temperature hybrid energy systems. Because of the ability to greatly vary gas compositions (both type and quantity), it can be used to test materials for future heat exchangers, steam generators, circulators, seals, and instrument and control components.

\subsection{Background}

In response to a national strategic need identified in the Energy Policy Act of 2005 to promote reliance on safe, clean, economic nuclear energy and to establish a greenhouse-gas-free technology for the production of hydrogen, the Department of Energy (DOE) defined a mission need to develop new, advanced nuclear reactor and hydrogen production technologies. The Next Generation Nuclear Plant (NGNP) represents an integration of high-temperature reactor technology with advanced capabilities for producing hydrogen, electricity, and/or process heat. Battelle Energy Alliance, LLC is advancing this technology at INL in conjunction with partners from other national laboratories, industry and academia.

Multiple INL organizations collaborated to establish the MISTER capability at INL, and the first test planned and currently underway supports the selection of HTSE materials. To this end, NGNP Process Heat Applications and HTSE research and development (R\&D) organizations were fully integrated during development. MISTER and HTSE test equipment are consequently co-located in the Bonneville County Technology Center (BCTC).

Significant work was accomplished in FY 2010 and continues in FY 2011 in selecting, defining, and evaluating potential industrial applications that benefit from NGNP integrated hydrogen production. That work indicates there is a need to demonstrate material performance, such as corrosion, in gaseous heat transfer system piping and components that connect the industrial applications. MISTER is a capability that can test corrosion of potential materials in a variety of gas environments. 
MISTER complements other test capability currently being fabricated or planned to support development of technologies needed for NGNP deployment. Although each of these capabilities can provide important, unique data for high temperature and pressure components, MISTER is designed to replicate the aggressive mixed gas environments expected for process heat applications components on multiple small specimens to measure corrosion in specific conditions. The high temperature oxygen- and hydrogen-based gas streams at the anode and cathode of the HTSE solid-oxide electrolysis cells (SOECs) are two of these environments. Hence, scoping tests of potential materials for use in these HTSE gas streams were selected to define operating conditions for the first MISTER tests. 


\section{MISTER DESIGN}

\subsection{Design Overview}

MISTER will provide the desired environments for material testing through two independent piping systems, one for flammable mixtures (hydrogen, $\mathrm{CO}_{2}$, etc.) and another for oxidizing mixtures (oxygen, air, etc.). The flow path for each is a once-through design where the gases are mixed, heated, passed over the samples, and then exhausted by venting through the roof of the laboratory. The gas streams are piped in a configuration that enables gas exposure of different components, specimen configurations or bipolar corrosion measurements during the same experimental run. Bipolar testing refers to the ability to flow different gas compositions on opposing sides of the same sample. The two parallel streams share a co-located gas supply system, and all tube fittings are positioned outside the furnace. Piping system is assembled with standard Swagelok-type fittings and tubing with a maximum allowable working pressure of $7 \mathrm{MPa}(1,000 \mathrm{psi})$. The flammable mixtures piping system is electrically grounded and bonded. A conceptual diagram of the MISTER system is shown in Figure 1. No isolation valves are present in the piping from the furnace to the vent so over-pressurization from heating is not possible.

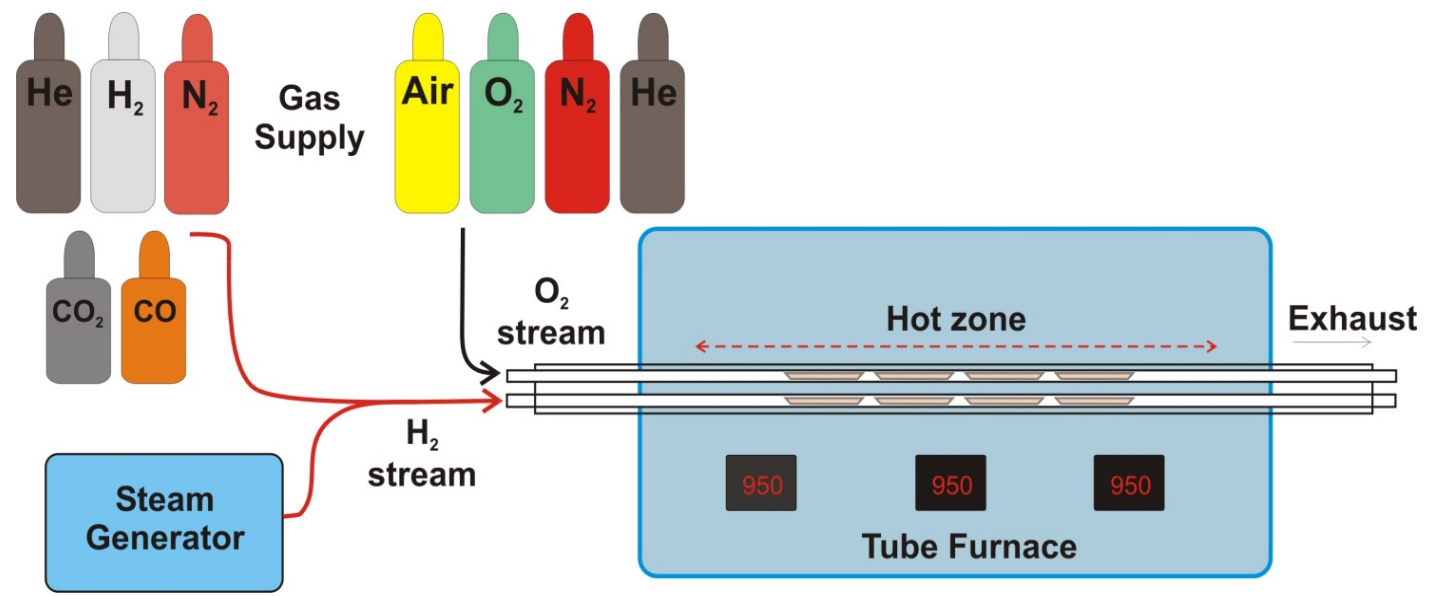

Figure 1. Conceptual drawing of MISTER.

The configuration allows seven gases to be connected to the gas supply: hydrogen, nitrogen, carbon monoxide, carbon dioxide, compressed air, oxygen, and helium. These gases are supplied from compressed gas cylinders. Compressed air can be supplied from building utilities for low-pressure testing. To accommodate long experiments, gas cylinders are connected to a changeover regulator assembly that allows bottle change-out without loss of gas flow. Pressure relief valves are installed in each supply line and set to $7 \mathrm{MPa}(1,000 \mathrm{psi})$. Other gases can also be used if they are compatible with gas chemistry and tubing materials.

Figure 2 shows a photo of the MISTER system in the BCTC with the experimental control monitors in front of the tube furnace. At the inlet to the furnace (between the furnace and the wall) is the rack that holds the mass flow controllers, steam generator, humidifier, and other gas conditioning components. To the right of the photo (not shown) are the compressed cylinders for gas supply. 


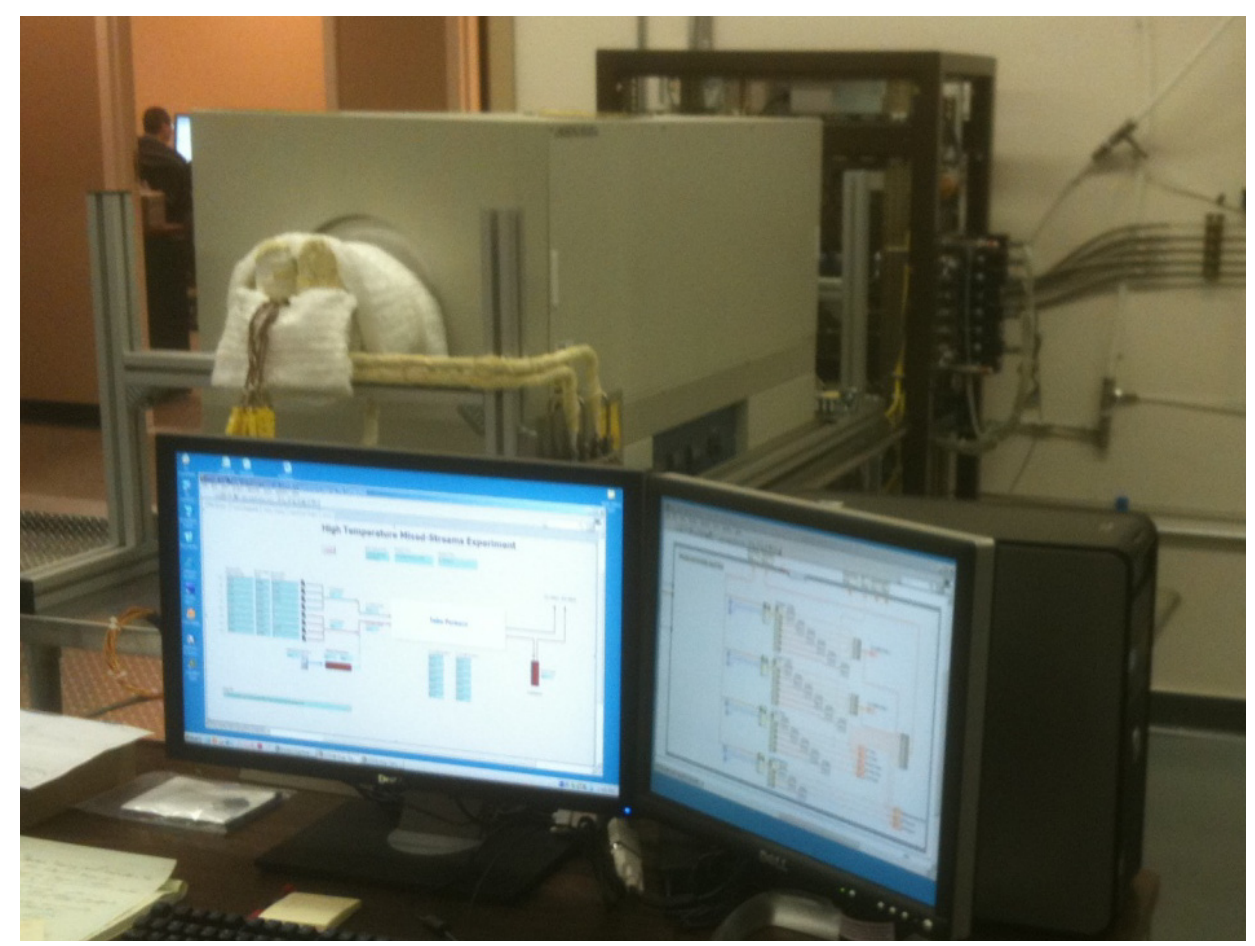

Figure 2. MISTER System in BCTC Bay 9.

\subsection{Design Process}

Early design and scoping efforts identified an opportunity to build upon INL experience with earlier high temperature materials testing with similar gases. A complete process model of MISTER was developed using HYSYS process modeling software to evaluate gas mixtures, flows, pressures, and temperatures to predict system performance and identify areas of concern. It also allowed a degree of fine-tuning to ensure that the testing environments replicate expected future material demands. The piping and instrumentation diagram (P\&ID) is shown in Figure 3. A hazardous gas shutdown and purge system was designed to automatically place the experiment in a safe state in response to the BCTC Bay 9 Hazardous Gas Alarm System, while preventing damage to experiment material samples. The result was that the MISTER design expanded test capabilities to include higher temperature, pressurized gas streams, and additional gas mixing capabilities.

Automation such as an uninterruptible power supply (UPS) system for the data acquisition/system controller computer system is incorporated, making the system reliable for unattended operation. In the event a long power failure exceeds the capacity of the UPS, resulting in failure of the system-controller computer, the furnace simply cools down and the gas flows stop. No hazard exists from loss of power, even if the power subsequently comes back on, because of the automatic gas shutoff positions. The hazardous gas supply valves will fail shut on a loss of power and the helium gas supply valve will fail open to perform a purge of the system. 


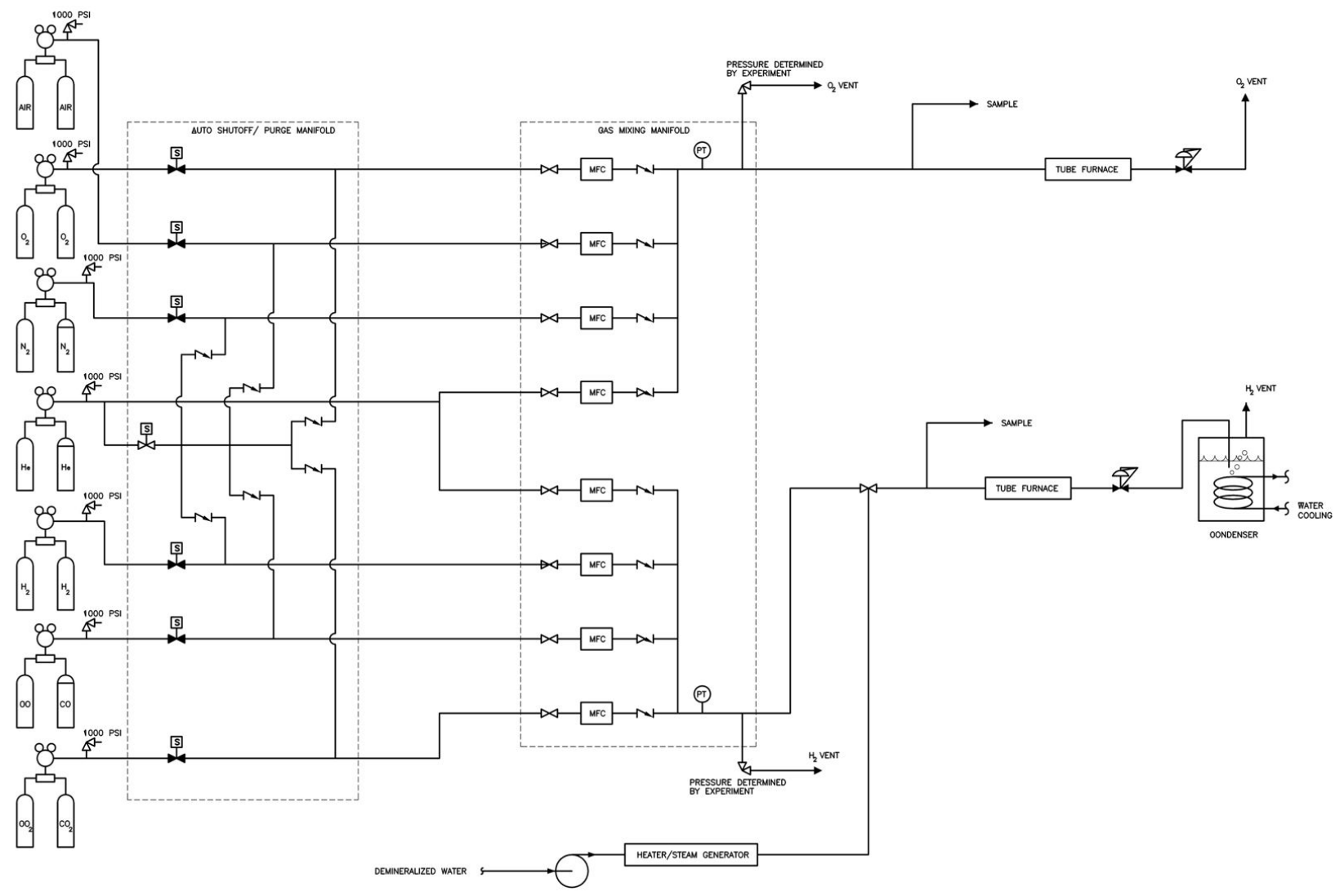

Figure 3. MISTER P\&ID.

\subsection{Quality Assurance}

A Quality Level Determination (QLD) performed on the MISTER experiment design and assembly determined it to be Quality Level (QL) 3. Because the first experiment is a scoping test, the data use was also judged to be QL-3. Separate QLDs for each test matrix will be performed for future experiments and the quality level for each will be determined based on data use. It is anticipated that if the data's use is for ASME code development, design of critical systems, or supporting high impact programmatic decisions, additional rigor may be required, resulting in a QL-2 determination for that future experiment. Examples of the impact of a QL-2 determination might be thermocouple calibrations, tighter controls of gas impurities, or stricter chain of custody requirements for the specimens. Nothing in the design and fabrication of MISTER would prevent application of such rigorous controls if the data use required it.

\subsection{Safety Authorization and Hazard Mitigations}

The work management process for INL research and development was used in the MISTER design to ensure that all stages of work (planning, performing, and providing feedback) were conducted safely. Laboratory Instruction LI-1607-10-BCTC, "High Temperature Mixed-Streams Experiment," was developed and formally reviewed by personnel from multiple organizations and work disciplines. The LI was approved for use on May 11, 2010, identifying the following potential hazards and their mitigations with engineering and administrative controls:

1. Buildup of hydrogen in the laboratory. Hydrogen gas mixed with air can create an explosion hazard. Confining the hydrogen gas within a fully sealed and leak-checked flow system mitigated this potential hazard. The potential explosion hazard is further mitigated by the means of the laboratory 
gas monitoring system. A hydrogen sensor provides a warning alarm at $10 \%$ of the lower flammability level (LFL). An evacuation alarm is set at $25 \%$ of LFL, which also actuates an automatic shut-off valve to terminate hydrogen flow to the experiment.

2. Buildup of oxygen in the laboratory. Oxygen gas concentrations above $23 \%$ increase flammability of many materials and oil, grease, and dirt out of the oxygen piping in accordance with LI-1370-08-BCTC, "Cleaning Pressure Systems for Oxygen Service." Confining the oxygen gas within a fully sealed and leak-checked flow system also mitigates this hazard. Exhaust gases containing oxygen will be directly vented to the outside via a laboratory exhaust duct. An oxygen sensor is wall-mounted near the experiment and provides a warning alarm at $21.5 \%$ oxygen content in the atmosphere. At $22.5 \%$, the system will actuate an automatic shut-off valve on the oxygen inlet flow line that will terminate oxygen flow.

3. Buildup of $\mathrm{CO}_{2}$ in the laboratory. Although MISTER was designed, fabricated, and authorized to use $\mathrm{CO}_{2}$ gas for future experiments, no $\mathrm{CO}_{2}$ gas is being used in the current experiment. Alarm and isolation strategies for $\mathrm{CO}_{2}$ use the Threshold Limit Value (TLV) for $\mathrm{CO}_{2}$ of 5,000 ppm $(0.5 \%)$ as a design basis. $\mathrm{A} \mathrm{CO}_{2}$ sensor is wall-mounted near the experiment at the recommended 3-ft level. This system will provide a warning alarm at $2,500 \mathrm{ppm}$ (one-half of the TLV) and at the TLV, the system will actuate an automatic shut-off valve on the $\mathrm{CO}_{2}$ inlet flow line that will terminate $\mathrm{CO}_{2}$ flow. The $\mathrm{CO}_{2}$ system is fully sealed and a leak-check will be performed before using this gas in MISTER.

4. Exposure to CO (carbon monoxide). Although MISTER was designed, fabricated, and authorized to use $\mathrm{CO}$ gas for future experiments, no $\mathrm{CO}$ gas is being used in the current experiment. Alarm and isolation strategies for $\mathrm{CO}$ follow the strategies defined in area chemical hygiene plan LWP-14620. Therefore, the laboratory area will be posted accordingly. To mitigate this potential hazard, the CO will flow through a completely sealed system and a CO sensor provides a warning alarm at $12.5 \mathrm{ppm}$ CO (one-half TLV). An evacuation alarm will sound at the TLV level of $25 \mathrm{ppm}$ and the system will actuate an automatic shut-off valve on the $\mathrm{CO}$ inlet flow line that will terminate $\mathrm{CO}$ flow. The $\mathrm{CO}$ system will be fully leak-checked prior to using this gas in MISTER.

In the event that any of the gases cause the gas-hazard evacuation alarm to sound, all personnel will exit the laboratory immediately. The procedures in EAR-683, "BCTC Bay 9 Hazardous Gas Alarms," will be followed in the event a hazardous gas alarm activates in the laboratory. 


\section{MISTER ASSEMBLY}

\subsection{Legacy Equipment-High Temperature Corrosion Experiment}

The assembly of the MISTER experiment began with the retrieval of legacy equipment from the High Temperature Corrosion experiment. The earlier experiment was designed and assembled in 2006 and testing was performed in 2007. The High Temperature Corrosion Experiment performed materials scoping studies in 2007, supporting early High Temperature Electrolysis program work. Following these tests, the experiment was disassembled and the more significant equipment and assemblies were packaged and shipped to INL bonded storage. In early March 2010, the legacy equipment was retrieved from bonded storage and staged in BCTC Bay 9. The major equipment items useful for MISTER were all found to be in excellent condition. These items included the large three-zone tube furnace, steam generator lines, steam condenser, mass flow controllers, and other piping and manifold components.

\subsection{Facility Modifications}

Several modifications to the BCTC Bay 9 lab space were made to support the MISTER experiment. Electrical modifications included a new $50 \mathrm{Amp}, 208$ Volt circuit supporting the large tube furnace to supply a cord-and-plug connection. Data and voice communications lines were provided and a link to the Bay 9 hazardous gas alarm signal was made. Mechanical modifications were completed to install building compressed air, potable water, and deionized water connections near the MISTER location. The existing Bay 9 hydrogen and oxygen vents were modified to allow connection of the appropriate gas streams.

\subsection{MISTER Assembly}

The physical assembly of the MISTER experiment was completed in September 2010 and the Labview computer control programming for the experiment was completed in October 2010. Major subassemblies of the MISTER experiment are as following:

- Gas supply and automatic shutoff/purge manifold. To accommodate long experiment runs, gas cylinders were connected to a changeover regulator assembly, which allows bottle change-out without loss of gas flow. Upon receipt of a shutdown signal, six normally closed (fail-closed) solenoid valves isolate the hazardous gas supplies and a normally open (fail-open) solenoid valve initiates inert purge gas $(\mathrm{He})$ through all lines. Check valves prevent gas mixing in the automatic shutoff/purge system.

- Gas mixing manifold. The gas mixing manifold includes individual mass flow controllers for each gas producing the desired gas mixtures for the experimental campaign. Up to four individual gases can be mixed to produce each of the two outlet streams.

- Steam addition. A metering pump and steam generator were used to add steam to the flammable mixtures gas stream. The associated lines are heat-traced to prevent steam condensation.

- Tube furnace. The two gas streams flow through the furnace in metal pipe or tubes, large enough to place small sample coupons inside. The tube furnace has a maximum operating temperature of $1100^{\circ} \mathrm{C}$ with a $90-\mathrm{cm}$ (36-inch) long heated chamber with three zones of control.

- Outlet configuration. The oxidizer stream discharges directly to the building $\mathrm{O}_{2}$ vent. The flammable stream is directed to a steam condenser to both cool and remove water from the stream. The outlet of the steam condenser proceeds directly to a building $\mathrm{H}_{2}$ vent.

Following the experiment assembly, the oxygen mixture pressure system was cleaned as noted in Section 2.4 to remove all contaminants that could pose a flammability concern when exposed to high $\mathrm{O}_{2}$ concentrations. This included disconnecting the pressure system into sections, cleaning the system, drying 
the system, reassembly and leak checking the system, and disposing of and recycling the cleaning solution.

\subsection{Instrument Calibration}

The instruments maintained and calibrated by INL calibration services are mass flow controllers, a metering pump, and pressure transducers. Factory calibration of the new devices provided sufficient calibration rigor during the first calibration interval. Other instruments, such as thermocouples, pressure regulators, and back pressure control valves that were used to control the test system for these initial scoping tests did not require calibration because the corrosion data is for scoping purposes. Since calibrations are routine maintenance that is frequently and routinely performed at INL, demonstrating them was deemed unnecessary for the operation of MISTER. Response to control systems was checked during shakedown testing. Future testing for uses such as ASME Code qualification and generation of design data will be performed under appropriate test procedures that specify the needed calibrations.

\subsection{Physical Description of MISTER Subsystems}

\subsubsection{Gas Supply and Automatic Shutoff/Purge Manifold}

A hazardous gas monitoring system, employed in the laboratory for safety, monitors four gases (CO, $\mathrm{CO}_{2}$, hydrogen, and oxygen) in two locations. The system has relay outputs, display readout, visual and audible alarms, and an auto phone dialer. The relay outputs are used to automatically shut down the experimental gas flow if any gas alarm is activated. Upon receipt of a shutdown signal, six normally closed (fail-closed) solenoid valves isolate the hazardous gas supplies and a normally open (fail-open) solenoid valve initiates inert purge gas (helium) through all lines. Check valves prevent gas mixing in the automatic shutoff/purge system.

The outlet of the automatic shutoff/purge system provides feed to the gas mixing manifold through patch lines allowing reconfiguration of the specific gases supplied to each port. For example, compatible gases such as helium and nitrogen can be supplied to one or both of the flammable and oxidizer mixture streams.

\subsubsection{Gas Mixing Manifold}

The discharge from the gas supply system feeds the gas mixing manifold, including the individual mass flow controllers for each gas to produce the desired gas mixtures for the experimental campaign. Up to four individual gases can be mixed to produce each of the two separate outlet streams. Pressure relief valves on the outlet streams are set below the maximum pressure of the specific experiment components running through the remainder of the flow system. The maximum allowable working pressure of the gas mixing manifold is also set at $7 \mathrm{MPa}(1,000 \mathrm{psi})$.

\subsubsection{Steam Addition}

A metering pump and electric powered steam generator are used to add steam to the flammable mixtures gas stream. The associated lines are heat-traced to prevent steam condensation. The metering pump controls the steam addition and hence, the steam-to-gas ratio in the affected outlet stream.

\subsubsection{Tube Furnace}

The two gas streams flow through the furnace into $2.5 \mathrm{~cm}(1 \mathrm{inch})$ diameter metal pipes that are large enough to place small sample coupons inside. The tube furnace is a Lindberg Model 55666 B COM with a maximum operating temperature of $1100^{\circ} \mathrm{C}$. It has a $90 \mathrm{~cm}$ (36 inch) heated chamber with three zones 
of control (first zone is 9 inches, middle zone 18 inches, last zone 9 inches) in a double-shell construction. The furnace is rated for $11 \mathrm{~kW}$ at $240 \mathrm{VAC}$. Since the laboratory supplies only $208 \mathrm{VAC}$, the furnace can produce $8.3 \mathrm{~kW}$. The tube furnace is controlled with three separate Yokogawa UP150 programmable controllers with dual light-emitting diode displays of the set point and actual temperature. The tube furnace also has separate over-temperature protection. This consists of a digital high-limit controller with separate thermocouple and magnetic contactor disconnect on the heating elements.

\subsubsection{Outlet Configuration}

Atmospheric pressure experiments do not have valves between the furnace and the vents. Future pressurized testing will require that a backpressure regulator valve be installed downstream of the furnace to provide pressure control in the system. The oxidizer stream will discharge directly to the building oxygen vent. The flammable stream will be directed to a steam condenser to both cool and remove water from the stream. The outlet of the steam condenser will proceed directly to a building hydrogen vent.

\subsection{Shakedown Testing}

Shakedown testing was performed during the week of November 8, 2010, using test steps outlined in a draft test instruction. The purpose of the shakedown test was to demonstrate the functionality of the overall system at high temperature, with gas and steam flow, and under computer control during unattended operation. A second purpose was to identify and implement improvements for the experiment. The test did not include material samples in the process lines.

The shakedown test began on Monday morning (November 8, 2010) with a heat-up phase using nitrogen flow through both process lines. The system stabilized at $825^{\circ} \mathrm{C}$ and was held overnight to evaluate system stability during unattended operation. Hazardous gas flow of $\mathrm{H}_{2} / \mathrm{N}_{2} /$ steam and $\mathrm{O}_{2} / \mathrm{N}_{2}$ was initiated Tuesday morning and the system ran continuously until Friday morning. During the total run time of 93 hours, the system performance was very stable with all measured parameters holding steady throughout the week. Following the shakedown test, several items were identified to optimize the performance and control of the test rig and provide additional performance information to the operator. These items were addressed prior to starting the extended test run with sample materials in January 2011. Improvements included installing check valves in the gas supply lines to prevent back flow from the system to the gas regulators. A gas flow gauge was installed in the oxygen vent line to provide a visual indication of discharge flow, and thermocouples were added to the furnace outlet lines to measure exit temperature.

During disassembly of the discharge end of the furnace process lines, it was very difficult to break the fittings loose. The discharge fittings are stainless steel and appear to have reached higher temperatures than anticipated. Of concern was that the force needed to break the fittings loose might overload and damage the furnace alumina tube. A bracket to reduce the disassembly loads was designed and installed in the system. Inconel tube fittings (long-lead item) were ordered to replace the existing stainless steel fittings, which should eliminate the potential for galling or cross-threading at the higher-than-expected temperature.

These improvements were completed during December 2010, and the MISTER experiment was judged ready for use. Actual material testing began Tuesday morning, January 11, 2011. 


\section{OPERATIONS}

Alloy specimens were placed on ceramic "boats" on January 11, 2011, and inserted into the MISTER Hastelloy 214 tubes (see figures 4-8). Specimens of four alloys are now being simultaneously exposed to environments simulating the cathode (hydrogen stream) and anode (oxygen stream) gases. This test uses gas composition of $70 \%$ hydrogen and 30\% water for hydrogen stream and 50\% nitrogen gas and 50\% oxygen for the oxygen stream at $800^{\circ} \mathrm{C}$. These conditions were identified during modeling of the HTSE system, except that ambient pressure is used because of current experimental limitations and because the current test matrix is for preliminary scoping. A commercial HTSE plant is expected to operate at a pressure of $5 \mathrm{MPa}$ (725 psi) and high pressure testing will be needed eventually to demonstrate viability of the technology at larger scales. Actual specimen exposure was included in the start-up testing of MISTER because it allows identification of specimen management issues during a scoping test when the consequences of lost data are relatively low.

\subsection{Test Materials Selection}

Initial testing in MISTER supports HTSE technology development. Exterior to the actual SOECs, HTSE system components such as gas manifolds are exposed to super-heated $\left(800-950^{\circ} \mathrm{C}\right)$ hydrogen/steam and oxygen/nitrogen gas mixtures. Corrosion products from potential balance-of-plant (BOP) materials may contaminate SOECs and cause reduced performance. It is therefore essential to select and qualify materials with excellent corrosion performance under reducing and/or oxidizing environments at temperatures up to $950^{\circ} \mathrm{C}$ for lifetimes up to 40,000 hours.

Previous INL test results showed that about half of the alloys tested appeared quite stable to oxidation and spalling after 1,000 hours. In particular, alumina-forming alloys showed very thin oxide films and minimal weight gain. Spinel $\left(\mathrm{MnCr}_{2} \mathrm{O}_{4}\right)$ forming alloys such as Haynes 230 and HR-120 were also promising. Incoloy $800 \mathrm{H}$ and other chromia forming alloys showed mixed results, where significant spalling was observed in the oxygen/nitrogen simulated stream. Initial MISTER testing will validate operation of the test apparatus and develop some preliminary scoping data for candidate material selection. Recent modeling work within the HTSE group targets an operating temperature of $800^{\circ} \mathrm{C}$ at $5 \mathrm{MPa}$. A variety of gas mixtures are present within the HTSE system, but the first test will use a median value of $70 \%$ hydrogen $/ 30 \%$ steam for the cathode stream and $50 \%$ oxygen $/ 50 \%$ nitrogen for the anode stream.

Table 1 provides a list of commercial alloys selected for the initial testing. The first three alloys were selected because of superior performance in previous INL BOP testing. The final alloy was chosen as an alloy that has been selected for fabrication of other NGNP heat transport system components. Alloy $800 \mathrm{H}$ is already listed in the ASME nuclear section (ASME Code Section III Division 1), although the maximum use temperature and time needs

Table 1. Alloys selected for MISTER testing.

\begin{tabular}{|lll|}
\hline \multicolumn{1}{|c}{ Alloy } & Oxide & \multicolumn{1}{c|}{$\begin{array}{c}\text { Expected } \\
\text { Performance }\end{array}$} \\
\hline Haynes 214 & Alumina & Excellent \\
Haynes 230 & chromia & Excellent \\
Haynes HR-120 & chromia & Good \\
Incoloy $800 \mathrm{H}$ & chromia & Good $*$ \\
\hline$* \quad$ ASME codified for nuclear applications at lower temperatures. \\
\hline
\end{tabular}
to be increased if it is to be used as a pressure boundary material in HTSE gas streams at $800^{\circ} \mathrm{C}$.

The test matrix specified that each material type be tested in both the hydrogen and oxygen streams and that a sample of each material be removed after approximately 2 days, 1 week, 3 weeks, and 6 weeks, making a total of 32 samples. The tests have been and will continue to be performed at $800^{\circ} \mathrm{C}$. The test matrix for the cathode gas environment (hydrogen) is shown in Table 2 with a hydrogen feed rate of $0.5 \mathrm{~L}$ per minute and water feed rate of $0.161 \mathrm{~mL}$ per minute. The test matrix for the anode gas environment (oxygen) is shown in Table 3, with both oxygen and nitrogen feed rates of $0.292 \mathrm{~L}$ per minute. 
Table 2. Test matrix for testing HTSE cathode gas environment.

\begin{tabular}{|l|l|l|c|}
\hline No. & \multicolumn{1}{|c|}{ Alloy } & \multicolumn{1}{|c|}{ Type } & $\begin{array}{c}\text { Approx } \\
\text { Exposure } \\
\text { (hrs) }\end{array}$ \\
\hline 1 & HR-120 & Chromia & 48 \\
\hline 2 & HR-120 & Chromia & 168 \\
\hline 3 & HR-120 & Chromia & 504 \\
\hline 4 & HR-120 & Chromia & 1,000 \\
\hline 5 & H214 & Alumina & 48 \\
\hline 6 & H214 & Alumina & 168 \\
\hline 7 & H214 & Alumina & 504 \\
\hline 8 & H214 & Alumina & 1,000 \\
\hline 9 & H230 & Chromia & 48 \\
\hline 10 & H230 & Chromia & 168 \\
\hline 11 & H230 & Chromia & 504 \\
\hline 12 & H230 & Chromia & 1,000 \\
\hline 13 & $800 \mathrm{H}$ & Chromia & 48 \\
\hline 14 & $800 \mathrm{H}$ & Chromia & 168 \\
\hline 15 & $800 \mathrm{H}$ & Chromia & 504 \\
\hline 16 & $800 \mathrm{H}$ & Chromia & 1,000 \\
\hline
\end{tabular}

Table 3. Test matrix for testing HTSE anode gas environment.

\begin{tabular}{|l|l|l|c|}
\hline No. & \multicolumn{1}{|c|}{ Alloy } & \multicolumn{1}{c|}{ Type } & $\begin{array}{c}\text { Approx } \\
\text { Exposure } \\
\text { (hrs) }\end{array}$ \\
\hline 1 & HR-120 & Chromia & 48 \\
\hline 2 & HR-120 & Chromia & 168 \\
\hline 3 & HR-120 & Chromia & 504 \\
\hline 4 & HR-120 & Chromia & 1,000 \\
\hline 5 & H214 & Alumina & 48 \\
\hline 6 & H214 & Alumina & 168 \\
\hline 7 & H214 & Alumina & 504 \\
\hline 8 & H214 & Alumina & 1,000 \\
\hline 9 & H230 & Chromia & 48 \\
\hline 10 & H230 & Chromia & 168 \\
\hline 11 & H230 & Chromia & 504 \\
\hline 12 & H230 & Chromia & 1,000 \\
\hline 13 & $800 \mathrm{H}$ & Chromia & 48 \\
\hline 14 & $800 \mathrm{H}$ & Chromia & 168 \\
\hline 15 & $800 \mathrm{H}$ & Chromia & 504 \\
\hline 16 & $800 \mathrm{H}$ & Chromia & 1,000 \\
\hline
\end{tabular}

Thin plate specimens from 1/8-1/16-in.-thick plate were cut to $1 \times 1$-cm squares and a 600 -grit finish applied prior to testing. Witness specimens were characterized in as-received or as-prepared condition and gravimetric analysis is being used to measure weight change during the experiment.

\subsection{Specimen Insertion and Extraction}

Specimens were inserted into the MISTER furnace on January 10, 2011, and furnace heat-up was initiated. When the furnace reached operating temperature the morning of January 11, the specified gas streams were introduced. The gas streams were isolated on the afternoon of January 12 and the furnace was turned off so it could cool to allow the first set of specimens to be removed the morning of January 13. Furnace heat up and cool down requires from 6 to 8 hours. Figure 4 shows insertion of the samples in alumina boats.

Upon removal of the alumina boats on January 13, it was observed that one of the boats had cracked as shown in Figure 5. This boat was glued and both sets of boats reinserted with their samples. When the specimen and boats were removed on January 18, the repaired alumina boat (for the hydrogen gas stream) was replaced by a quartz boat as shown in Figure 6 . The undamaged alumina boat (for the oxygen gas stream) was reinserted. 


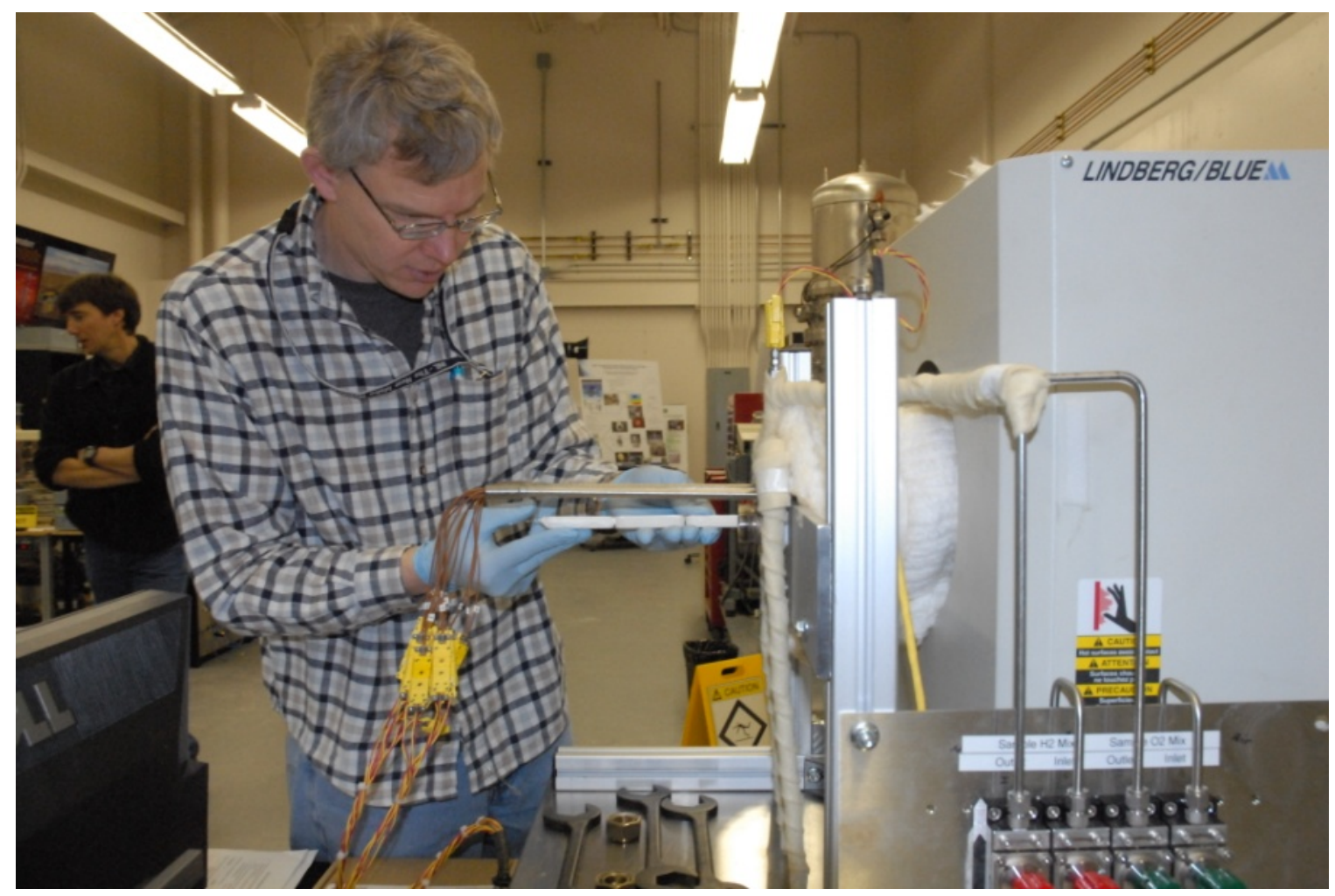

Figure 4. Insertion of specimen in alumina boats.

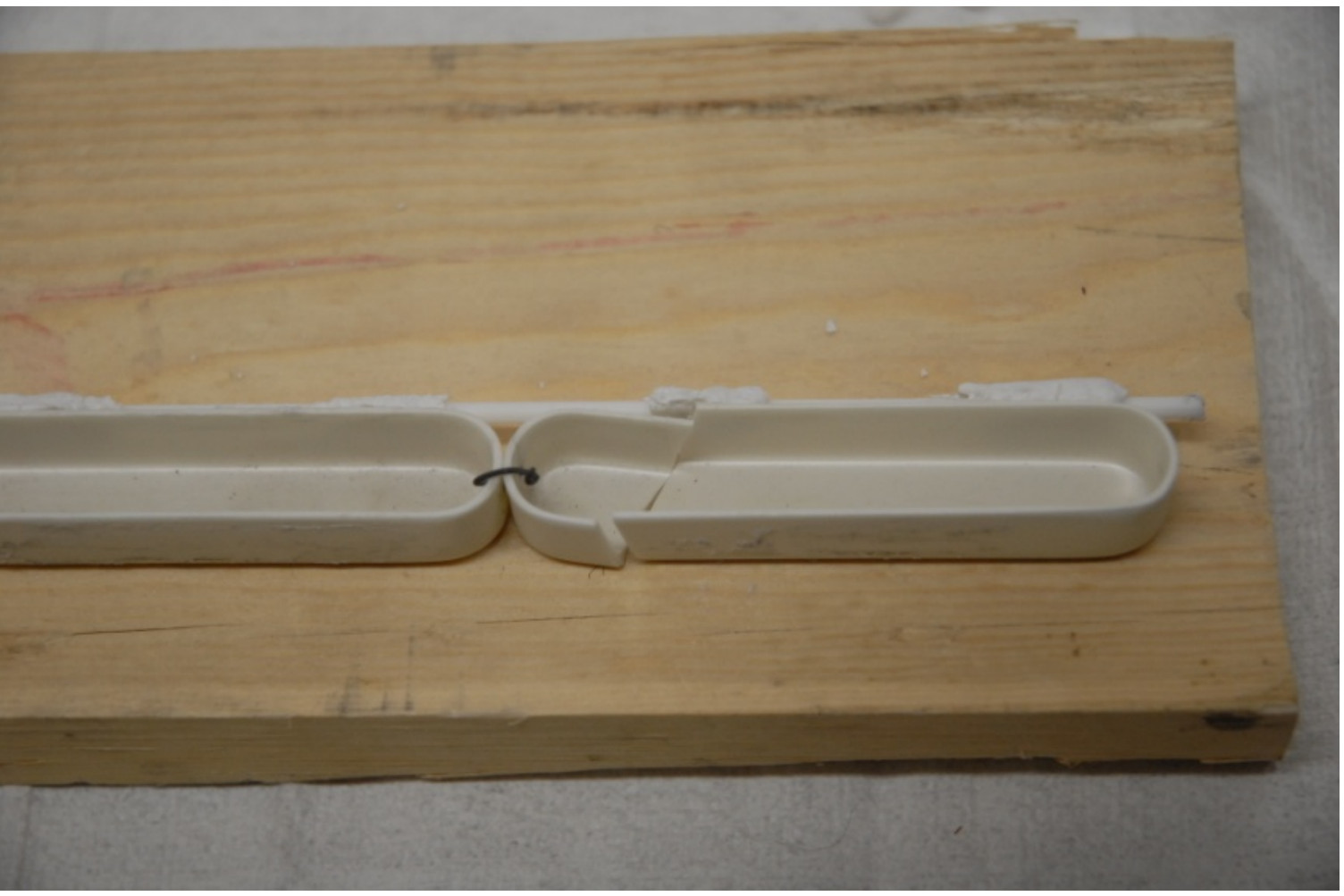

Figure 5. Cracked alumina boat at 2-day extraction. 


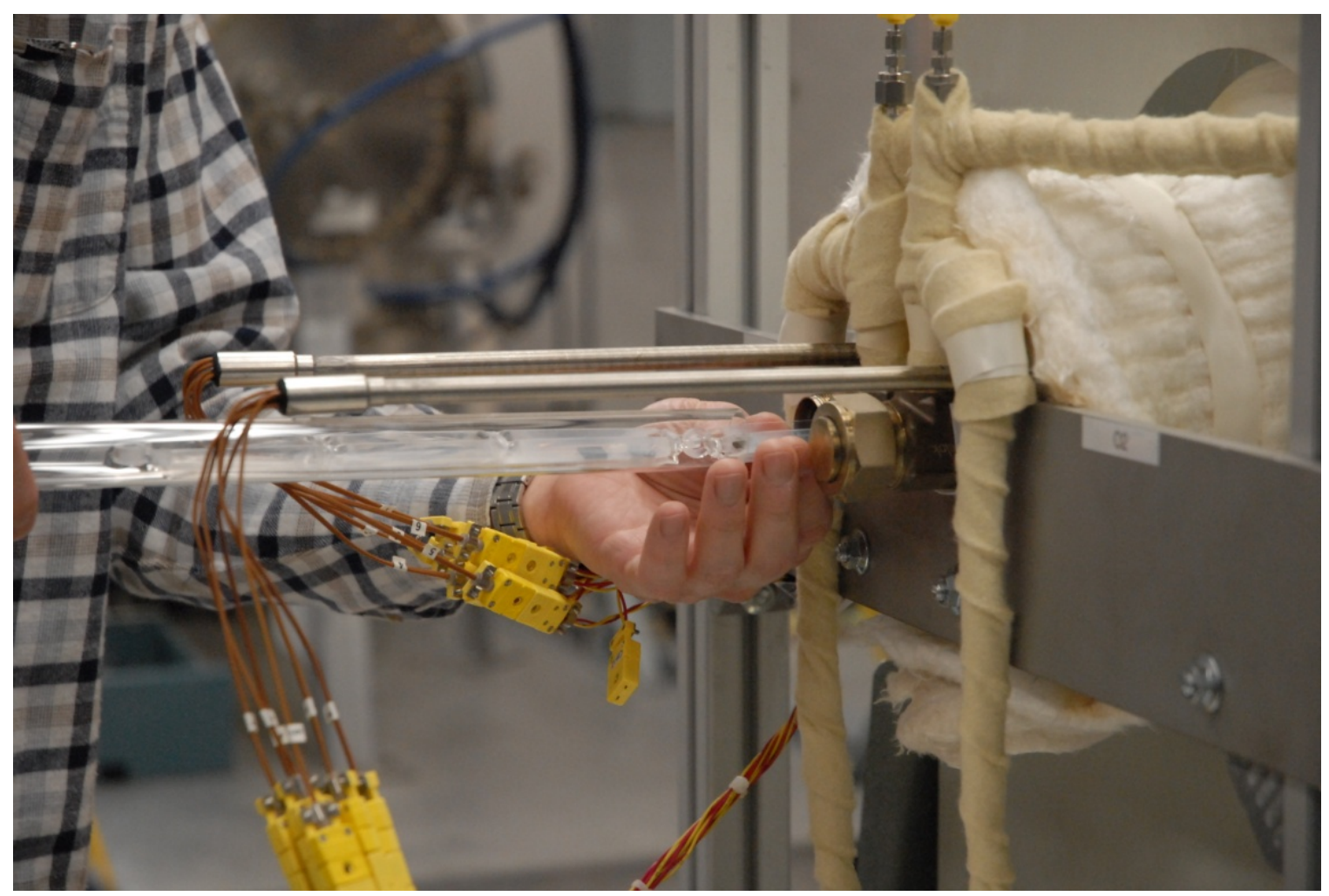

Figure 6. Loading specimen into MISTER using quartz boats.

There was no disruption to the sample schedule, as the technical staff made the necessary adjustments to allow the test to continue without interruption. The 3-week samples were removed on February 1, 2011, and the 6-week samples will be removed on February 22, 2011. A complete replacement of the alumina boats with the new design will be completed prior to any subsequent tests. The new boats include a design modification that makes them less likely to tip during insertion and removal.

\subsection{Specimen Examination}

Figures 7 and 8 show the appearance of the specimen after 25 and 125 hours in MISTER.

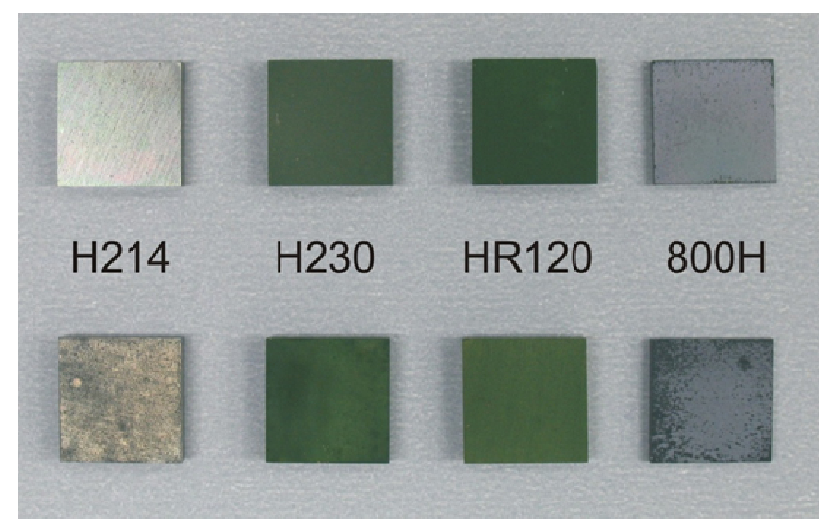

Figure 7. Color photograph of $1 \mathrm{~cm}^{2}$ specimens exposed to hydrogen/steam gas stream. Top row was exposed for 25 hours and bottom row for 125 hours.

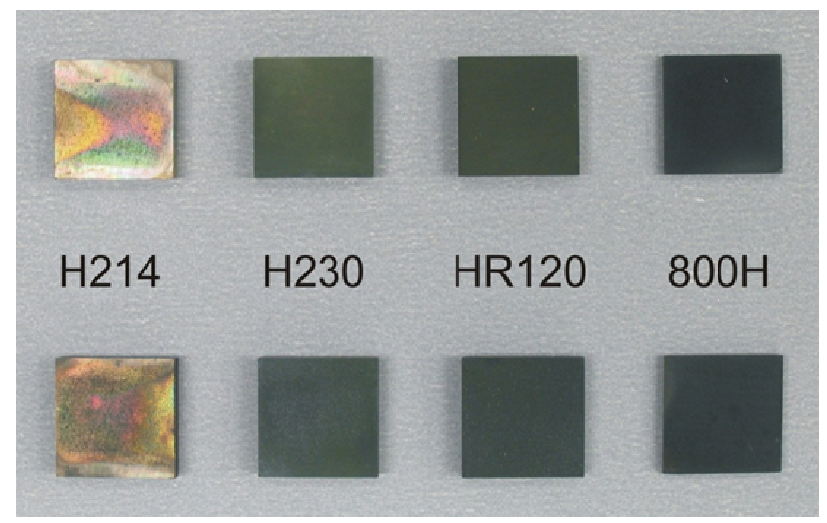

Figure 8. Color photograph of $1 \mathrm{~cm}^{2}$ specimens exposed to oxygen/nitrogen gas stream. Top row was exposed for 25 hours and bottom row for 125 hours. 
A detailed analysis of all test matrix specimens will be completed and reported at the end of the test. Specifically, a precision five-place balance will be used to measure the weight gain (or loss) resulting from exposure. Observations will be made concerning visual appearance between each exposure period and supplemented with macrographs. At the end of the final exposure, specimens will be thoroughly characterized. Initial observations will be made while observing under an optical microscope and scanning electron microscopy (SEM) will be performed on the surface and on polished cross-sections. The thickness of the oxide film for each cross-sectioned specimen will be determined from SEM micrographs. Energy dispersive spectroscopy of selected features will be performed as part of the SEM analysis. X-ray diffraction will be used to identify specific crystalline phases formed in the oxide films on the materials surfaces. 


\section{POTENTIAL FUTURE USES}

As noted earlier, MISTER is one of several complementary heat transport system test rigs that test materials, fabrication methods, and components. As a whole, these rigs provide the capability to perform the majority of the tests outlined by NGNP design suppliers to meet the early design data needs for the NGNP heat transport system. The test capability progression from early demonstration of materials and fabrication methods to component testing, shown in Figure 9, is described as follows.

- Small helium loop. The INL Materials Department designed and assembled a small helium test loop that can operate at up to $1000^{\circ} \mathrm{C}$ at atmospheric pressure. Precise control of contaminants within the helium is possible to maintain trace impurities at the concentrations expected in the NGNP. Exposure in this loop allows quantification of the helium's effects on material properties such as tensile strength. In addition to other materials properties tests, these results provide input to progressively larger tests of heat exchangers in progressively larger test rigs.

- Fabrication methods. Fabrication methods for heat exchangers and steam generators require demonstration prior to deployment. NGNP is developing diffusion weld processes for compact heat exchangers and is collaborating with the National Science Foundation to develop dissimilar metal welding processes for steam generators. Diffusion welding (also described as diffusion bonding) involves migration of atoms across a joint interface where the two metals are pressed together at an elevated temperature, usually between 50 and $70 \%$ of the melting point. Diffusion welded materials and dissimilar metal welds may be tested in MISTER to assess the effect of gaseous environments (corrosion, embrittlement, etc.) on the joints' performance.

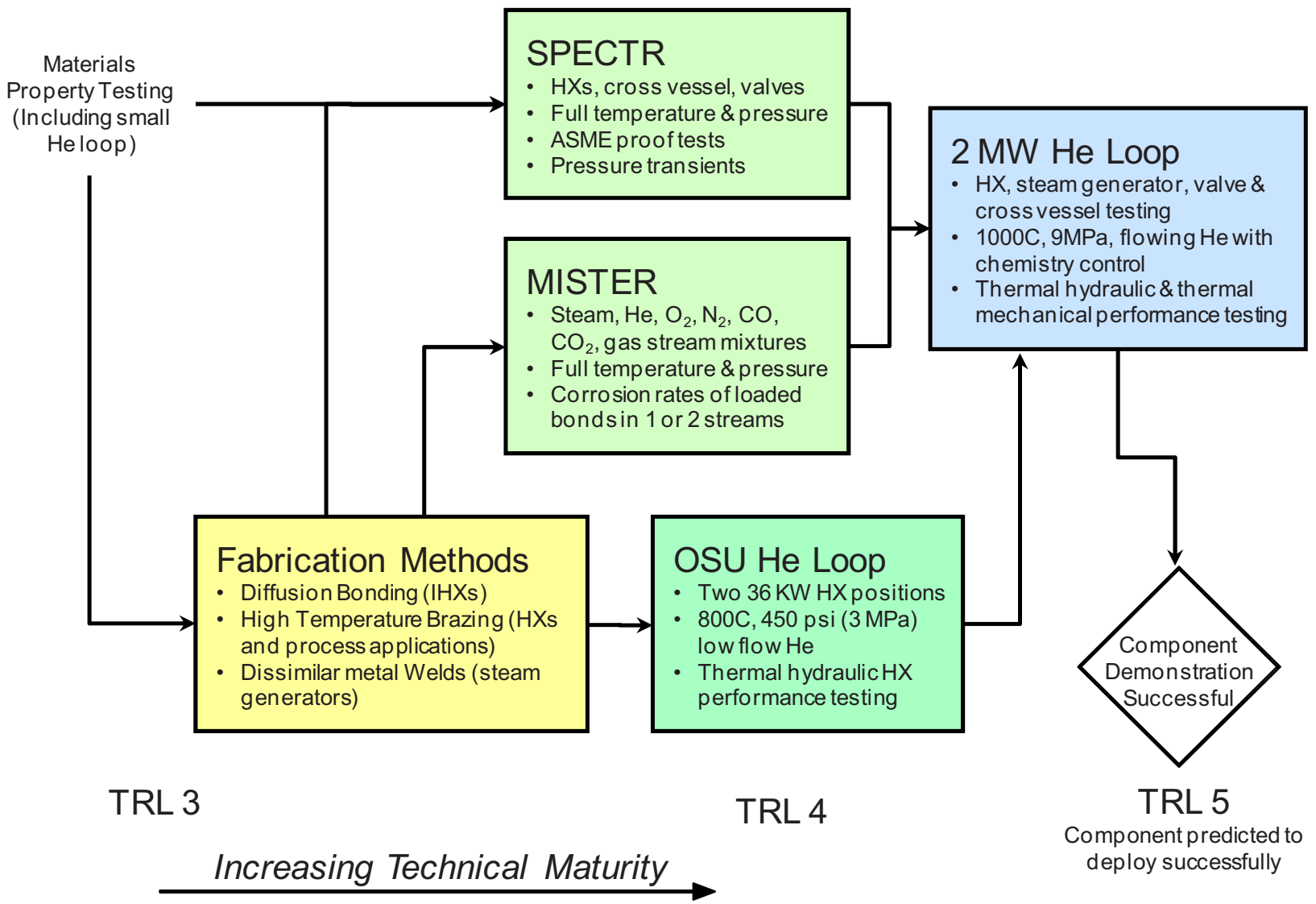

Figure 9. MISTER is part of a suite of complementary testing capabilities. 
- Ohio State University (OSU) helium loop. The OSU, with INL support, is developing a helium loop with two $36 \mathrm{~kW}$ positions for testing small unit cell heat exchangers. These tests can be performed at up to approximately $800^{\circ} \mathrm{C}$ and $3 \mathrm{MPa}(450 \mathrm{psi})$. Final start-up testing at full temperature and pressure is expected to be completed in late spring, 2011.

- $\quad$ SPECTR. The Small Pressure Cycling Test Rig (SPECTR) will be ready for operation in FY 2011 to test pressurized components at temperatures up to $1200^{\circ} \mathrm{C}$. This equipment will be capable of testing small heat exchanger cells (up to $150 \mathrm{lb}$ with dimensions less than 8 inches maximum) at differential pressures across the component of up to $9 \mathrm{MPa}(1,300 \mathrm{psi})$. This testing will occur in an inert gas environment that can withstand up to $1 \mathrm{MPa}(150 \mathrm{psi})$ if the component ruptures during testing. SPECTR's design specifications would allow pressurized testing of a stack of SOECs at $5 \mathrm{MPa}$. Successful completion of such a test would achieve a Technology Readiness Level of TRL-5 for the HTSE technology.

- 2 MWth loop. Preconceptual studies have been performed for the development of a 2 MWth loop that would allow completion of all identified tests needed to support the successful deployment of an intermediate heat exchanger. The tests were identified by three NGNP design teams. After heat exchanger demonstration, the loop would readily support further testing in support of hydrogen production, molten-salt reactors, and/or hybrid energy systems.

MISTER was designed and configured to make the system as flexible as possible to support a wide range of materials and test small components. The gas supply system is designed for $9 \mathrm{MPa}(1,000 \mathrm{psi})$ of almost any gas or gas mixture desired. Each of the two gas streams delivered to the furnace can be a controlled mixture of four separate gas streams, and each of these can be any mixture delivered in commercial gas cylinders.

The existing tube furnace has a $90 \mathrm{~cm}$ (36 inch) heated length, controlled in three zones making the temperature profile quite flexible. It has a 10-cm (4-in.)-diameter alumina tube through the center that allows a wide range of test articles and configurations to be inserted into the heated zones. The tube furnace can also accommodate a larger (up to a 6-in.-diameter) tube.

The MISTER test stand can be modified to allow any tube furnace configuration, kiln design, or other custom furnace to be placed between the inlet ports and outlet ports to provide even greater flexibility for testing materials and components. This might include:

- End loaded samples for high temperature stress strain research

- Sample testing with different gas mixtures across opposing surfaces

- High pressure/temperature tube/pipe stress/strain/creep studies

- Tube failure studies may be possible (with secondary shield piping)

- Cyclic affects of temperature and pressure

- Demonstrating coatings and special surface preparations.

MISTER could be used to test, select, and qualify materials for helical tube steam generators. For this component, high temperature helium is introduced at the top of the steam generator and flows down over the tubes. The water flows inside the tubes, entering the tube bundle at the bottom of the steam generator and passing through the helical economizer/evaporator/superheater section. It then passes through a vertical section that includes a bimetallic weld between the $2-1 / 4 \mathrm{Cr}-1$ Mo steel of the lower portion and the Incoloy Alloy $800 \mathrm{H}$ finishing superheater. Materials for these dissimilar metal welds can be tested in MISTER using prototypical gas environments. 
In additions to the NGNP Project, other DOE programs have demonstration needs with regard to material corrosion in gas streams. Hybrid energy systems that couple industrial processes to nuclear or new types of heat sources will require materials development in gas streams. This includes high temperature molten salt or liquid metal reactors. Life extension programs could use MISTER to expose steam generator materials and joined specimens to demonstrate the longer-life of new materials and fabrication techniques in realistic environments. 


\section{SUMMARY}

MISTER start-up was completed ahead of schedule on January 11, 2011. The current MISTER configuration represents an enhanced INL capability. In addition to materials testing for the HTSE system, tests of this nature can support materials testing programs for NGNP heat transport system components, coupled high temperature reactor-industrial processes, and hybrid energy systems. MISTER was thus designed and built so it could, with minor modifications, also provide high pressure testing up to $7 \mathrm{MPa}(1,000 \mathrm{psi})$. Additional modification could allow testing of materials subjected to load or cycling at these high temperatures and pressures within a variety of gas compositions. This will significantly advance the understanding of materials performance. Because of the ability to greatly vary gas compositions (both type and quantity), it can be used to test materials for future heat exchangers, steam generators, circulators, seals, and instrument and control components. 